\title{
Determinants of antibiotic prescription in paediatric patients: The case of two hospitals in Maputo, Mozambique
}

\author{
L G S Monteiro, ${ }^{1} \mathrm{MSc}$; A Chaúque, ${ }^{2} \mathrm{BSc}$; M P Barros, ${ }^{2} \mathrm{BSc}$; T R Irá ${ }^{1,2} \mathrm{BSc}$ \\ ${ }^{1}$ Faculty of Medicine, Eduardo Mondlane University, Maputo, Mozambique \\ ${ }^{2}$ Faculty of Sciences, Eduardo Mondlane University, Maputo, Mozambique \\ Corresponding author: L G S Monteiro (govilee@gmail.com)
}

\begin{abstract}
Background. The need for healthcare in paediatric patients is often due to respiratory diseases, acute diarrhoea and viral fever, which suggests a limited need for the use of antibiotics.

Objectives. To identify the determinants of antibiotic prescription in hospitalised paediatric patients in Mozambique.

Methods. A cross-sectional study was conducted between January and June 2015. A total of 454 medical prescriptions and clinical records of children aged 0 - 14 years from Hospital Central de Maputo (HCM) and Hospital Geral de Mavalane (HGM) were analysed.

Results. Antibiotics were used in $97.6 \%$ of the patients, with no significant differences $(p>0.05)$ in the prescription rates of the hospitals. The most commonly used antibiotics were beta-lactams (57.3\%), aminoglycosides (28.3\%) and co-trimoxazole (9.4\%). Antibiotics were prescribed in all cases of bronchopneumonia, fever, sepsis and acute gastroenteritis. For malaria and undefined diagnoses, antibiotics were prescribed $97.8 \%$ and $99.3 \%$ of cases, respectively. It was clear that most severe clinical conditions (odds ratio (OR) 9.06; $1.13-12.14$ ) and age <5 years (OR 5.47; 1.54 - 7.60) were treated with antibiotics.

Conclusion. The prescription of antibiotics for paediatric patients at both HCM and HGM was largely influenced by patients' clinical condition and age. It showed that physicians used an empirical approach, in the absence of laboratory tests, often leading to unnecessary antibiotic treatments with negative causative effects. Physicians should be encouraged to use an evidence-based approach for managing the cases correctly.
\end{abstract}

S Afr J Child Health 2017;11(3):109-111. DOI:10.7196/SAJCH.2017.v11i3.1224

Disease occurs at all ages, with pneumonia, malaria and diarrhoea being the most prevalent among paediatric cases. ${ }^{[1,2]}$ These and other childhood diseases can be caused by different pathogens including viruses, bacteria, fungi and protozoa and identifying the aetiological agents to establish the appropriate therapeutic approach is essential. ${ }^{[3-6]}$ According to van Buul et al. ${ }^{[7]}$ a physician's decision to use antibiotics is guided by six factors: the patient's clinical condition, advance care plans, using diagnostic resources, physician-perceived risks, the influence of family members, and the influence of the environment. Good prescription practice relies on determining the infection aetiology. Lack of resources can result in errors like prescribing antibiotics in the absence of a bacterial infection. ${ }^{[8,9]}$

The use of antibiotics for viral diseases and indeterminate fever is associated with poor clinical outcomes and increased costs for both patients and health systems, and it can result in resistance to antibiotics. ${ }^{[2,10-12]}$ To avoid antibiotic prescription errors and their consequences, physicians should consider the following: clinical and physiological condition of the patient, presence of bacterial infection, antibiotic spectrum, route of administration, pharmacokinetic and side-effects, as well as sociodemographic characteristics. ${ }^{[13]}$ In Mozambique, little is known about the factors that influence antibiotic prescriptions in paediatric patients, and therefore this study was conducted to identify the determinants of antibiotic prescription in hospitalised paediatric patients in Mozambique.

\section{Methods}

Between January and June 2015, a cross-sectional study was conducted in two hospitals in Maputo, Mozambique: the Hospital Central de Maputo (HCM), a level-4 hospital (national reference), and Hospital Geral de Mavalane (HGM), a level-3 hospital with a wide coverage range for Maputo. Although each facility has a microbiology laboratory to support diagnoses, the HGM has particularly limited resources and services. The paediatrics department of HCM has 338 beds, while HGM has 80 beds. Data from medical prescriptions and clinical records of children admitted to the emergency services were analysed to screen the use and the reasons for prescribing antibiotics.

According to the World Health Organization (WHO), a statistically viable antibiotic prescription analysis requires a minimum of 100 prescriptions. ${ }^{[13]}$ Therefore, a total of 454 patient records, with and without antibiotic prescriptions, were randomly selected from every third new child until the sample number conformed to WHO regulations. The information collected included demographic data, clinical conditions (as perceived by the physician and referred to in the medical records), common diseases, drugs and route of administration.

Data analyses were performed using the Statistical Package for Social Sciences version 19 (IBM Corp., USA). A logistical regression model was constructed to measure the influence of clinical and demographic characteristics on antibiotic use. Descriptive statistics were used to characterise the patients' antibiotic exposures and common routes of administration.

This study was approved by Comité Institucional de Bioética em Saúde da Faculdade de Medicina \& Hospital Central de Maputo (CIBS FM \& $H C M$ ). Additional authorisations were obtained from HGM and HCM.

\section{Results}

A total of 454 (229/665 from HCM and 225/860 from HGM) inpatient medical records were analysed. The majority $(81.6 \%)$ of patients were $<5$ years old and male (Table 1).

Bronchopneumonia was diagnosed in $36.6 \%$, followed by undefined diagnoses (30.4\%) (Table 2). Culture and sensitivity tests were performed on $16.2 \%(n=37)$ of HCM patients, but on no patients from HGM. Antibiotic prescription ratesdid not differ significantly $(p>0.05)$ between the twohospitals, with an average prescription rate of $97.6 \%$. Themostcommonly used antibiotics were beta-lactams (57.3\%), aminoglycosides (28.3\%), co-trimoxazole (9.4\%), chloramphenicol (2.2\%) and macrolides (1.0\%). Antibiotics were prescribed for children with bronchopneumonia (100\%), 
Table 1. Patients' demographic characteristics $(N=454)$

\begin{tabular}{llll}
\hline & \multicolumn{2}{c}{ Gender } & \\
\cline { 2 - 3 } Age, years & Male, $\boldsymbol{n}(\%)$ & Female, $\boldsymbol{n}(\%)$ & Total, $\boldsymbol{N}(\%)$ \\
\hline$\leq 2$ & $139(57.0)$ & $131(62.4)$ & $270(59.5)$ \\
$3-5$ & $60(24.6)$ & $36(17.1)$ & $96(21.1)$ \\
$6-10$ & $34(13.9)$ & $28(13.3)$ & $62(13.7)$ \\
$11-14$ & $11(4.5)$ & $15(7.1)$ & $26(5.7)$
\end{tabular}

Table 2. Common diagnoses referred to in medical records $(N=454)$

\begin{tabular}{|c|c|c|c|}
\hline \multirow[b]{2}{*}{ Diagnosis } & \multicolumn{2}{|c|}{ Hospital } & \multirow[b]{2}{*}{$\begin{array}{l}\text { Total, } \\
N(\%)\end{array}$} \\
\hline & $\begin{array}{l}\text { HCM, } \\
n(\%)\end{array}$ & $\begin{array}{l}\text { HGM, } \\
n(\%)\end{array}$ & \\
\hline Bronchopneumonia & $60(26.2)$ & $106(47.1)$ & $166(36.6)$ \\
\hline Malaria & $20(8.7)$ & $35(15.6)$ & $55(12.1)$ \\
\hline Fever & $14(6.1)$ & $9(4.0)$ & $23(5.1)$ \\
\hline Sepsis & $14(6.1)$ & $7(3.1)$ & $21(4.6)$ \\
\hline Acute gastroenteritis & $17(7.4)$ & $3(1.3)$ & $20(4.4)$ \\
\hline Multiple (undefined) & $84(36.7)$ & $54(24.0)$ & $138(30.4)$ \\
\hline Other $^{*}$ & $20(8.7)$ & $11(4.9)$ & $31(6.8)$ \\
\hline Total & $229(100)$ & $225(100)$ & $454(100)$ \\
\hline
\end{tabular}

malaria $(97.8 \%)$, fever $(100.0 \%)$, sepsis $(100.0 \%)$, acute gastroenteritis $(100.0 \%)$ and undefined diagnoses (99.3\%) (Table 3). The main route of antibiotic administration was parenteral (52.9\%), and the oral route was never exclusively used. The influence of the hospital environment, age of the patient, and clinical condition on antibiotic use were analysed. Both age and clinical condition were associated with the use of antibiotics (Table 4).

\section{Discussion}

This study indicates the excessive use of antibiotics in paediatric patients in Mozambique, regardless of the presence of bacterial infection, such as in malaria cases. A similar picture was found in Ethiopia ${ }^{[14]}$ and Nigeria. ${ }^{[15]}$ Possible explanations include drug availability, the presence of nonspecific infections, such as upper respiratory tract infections,
Table 4. Factors that influence the use of antibiotics

\begin{tabular}{llll}
\hline Factor (reference) & OR & 95\% CI & $p$-value \\
\hline Hospital level $(\mathrm{HCM})$ & 2.576 & $(0.654-6.37)$ & 0.18 \\
Clinical condition (severe) & 9.056 & $(1.134-12.328)$ & 0.03 \\
Gender (male) & 1.244 & $(0.359-4.313)$ & 0.73 \\
Age (<5 years) & 5.496 & $(1.541-7.595)$ & 0.009
\end{tabular}

$\mathrm{OR}=$ odds ratio $\mathrm{CI}=$ confidence interval; $\mathrm{HCM}=$ Hospital Central de Maputo.

empirical treatment, and prophylactic use. ${ }^{[17-19]}$ Empirical treatment and prophylactic use seem to be an effective solution for treatment, but they are frequently associated with poor clinical responses and the selection of antibiotic-resistant bacteria. ${ }^{[20]}$ The most common clinical conditions were bronchopneumonia, malaria, fever, sepsis and acute gastroenteritis. It is important to note the high proportion of undefined diagnoses due to limited laboratory studies. Confirming the presence of a bacterial infection is essential to guiding the use of antibiotics and improve clinical responses. Fisher et al. ${ }^{[21]}$ noted that the absence of laboratory studies to distinguish viral from bacterial infections may promote continued antibiotic use. Physicians should be encouraged to distinguish between viral and bacterial infections through laboratory testing to verify their diagnoses. Beta-lactams and aminoglycosides were among the most commonly used antibiotics, particularly the combination of ampicillin and gentamicin. The Mozambican Ministry of Health guidelines recommend this ampicillin/gentamicin combination in children $<2$ months old, and penicillin/chloramphenicol for children $>2$ months old. The ampicillin/gentamicin combination is recognised as a useful first-line treatment to manage bacterial sepsis in children $<5$ years old. ${ }^{[22]}$ Despite the fact that the oral route of administration is recommended for children, this was never used exclusively in either health facility ${ }^{[13,23]}$ The reasons for parenteral use included the clinical condition of the patient, the need for rapid action, the belief that injectable antibiotics are more potent, and the availability of injectable antibiotics. ${ }^{[1,16,23,24]}$ Children $<5$ years old received antibiotics more often than older children, possibly owing to more severe clinical conditions in younger patients. ${ }^{[25]}$ In addition, regardless of laboratory confirmation, clinical conditions played an important role in the use of antibiotics. Physicians' decisions were based on clinical conditions because of long turnaround times as a result of delayed responses from the laboratory. Physician-perceived risks associated with the need for rapid assistance may also have influenced the decisions to use antibiotics at HCM and HGM. ${ }^{[7]}$ Even though these perceptions were not explored, our findings highlight the excessive use of antibiotics in paediatrics patients, regardless of verified bacterial infections.

Table 3. Antibiotics used by clinical condition

\begin{tabular}{|c|c|c|c|c|c|c|c|c|}
\hline \multirow[b]{2}{*}{ Clinical condition } & \multicolumn{7}{|c|}{ Antibiotics } & \multirow[b]{2}{*}{ Total } \\
\hline & $\begin{array}{l}\text { Beta- } \\
\text { lactams, } \\
n(\%)\end{array}$ & $\begin{array}{l}\text { Aminogly- } \\
\text { cosides, } \\
n(\%)\end{array}$ & $\begin{array}{l}\text { Chloram- } \\
\text { phenicol, } \\
n(\%)\end{array}$ & $\begin{array}{l}\text { Quinolones, } \\
n(\%)\end{array}$ & $\begin{array}{l}\text { Tetracy- } \\
\text { cline, } \\
n(\%)\end{array}$ & $\begin{array}{l}\text { Co-trimoxa- } \\
\text { zole, } n(\%)\end{array}$ & $\begin{array}{l}\text { Macrolides, } \\
n(\%)\end{array}$ & \\
\hline Bronchopneumonia & $166(100)$ & $82(49.4)$ & $7(4.2)$ & $0(0.0)$ & $1(0.6)$ & $18(10.8)$ & $4(2.4)$ & 166 \\
\hline Malaria & $45(97.8)$ & $4(8.7)$ & $1(2.2)$ & $0(0.0)$ & $0(0.0)$ & $4(8.7)$ & $0(0.0)$ & 46 \\
\hline Fever & $23(100)$ & $11(47.8)$ & $1(4.3)$ & $0(0.0)$ & $0(0.0)$ & $1(4.3)$ & $0(0.0)$ & 23 \\
\hline Sepsis & $21(100)$ & $16(76.2)$ & $1(4.8)$ & $0(0.0)$ & $1(4.8)$ & $5(23.8)$ & $1(4.8)$ & 21 \\
\hline Acute gastroenteritis & $19(100)$ & $11(57.9)$ & $0(0.0)$ & $1(5.3)$ & $0(0.0)$ & $3(15.8)$ & $0(0.0)$ & 19 \\
\hline Multiple (undefined) & $136(99.3)$ & $78(56.9)$ & $6(4.4)$ & $5(3.6)$ & $5(3.6)$ & $36(26.3)$ & $3(2.2)$ & 137 \\
\hline Other* & $31(100)$ & $16(51.6)$ & $1(3.2)$ & $1(3.2)$ & $0(0.0)$ & $5(16.1)$ & $0(0.0)$ & 31 \\
\hline Total & 441 (99.5) & $218(49.2)$ & $17(3.8)$ & $7(1.6)$ & 7 (1.6) & $72(16.3)$ & $8(1.8)$ & 443 \\
\hline
\end{tabular}




\section{Conclusion}

The prescription of antibiotics for paediatric patients at both HCM and HGM was largely influenced by patients' clinical condition and age. It showed that physicians used an empirical approach, in the absence of laboratory tests, often leading to unnecessary antibiotic treatments with negative causative effects. Actions need to be taken to encourage physicians to use evidence-based approaches for managing the cases correctly.

Acknowledgements. To the Paediatrics Departments of HCM and HGM for providing us the data needed, and to all our colleagues.

Author contributions. LGSM, AC, MPB and TRI contributed equally to the research and writing up of the review.

Funding. None.

Conflicts of interest. None.

1. Feleke M, Yenet W, Lenjisa JL. Prescribing pattern of antibiotics in pediatric wards of Bishoftu Hospital, East Ethiopia. Int J Basic Clin Pharmacol 2013;2(6):718-722. https://doi.org/10.5455/2319-2003.ijbcp20131209

2. Kardas-Sloma L, Boelle PY, Opatowski L, Brun-Boisson C, Guilllemot D, Temime L. Impact of antibiotic exposure patterns on selection of communityassociated methicillin-resistant Staphylococcus aureus in hospital settings. Antimicrob Agents Chemother 2011;55(10):4888-4895. https://doi. org/10.1128/aac.01626-10

3. Kieninger E, Fuchs O, Latzin P, Frey U, Regamey N. Rhinovirus infections in infancy and early childhood. Eur Resp J 2013;41(2):443-452. https://doi. org/10.1183/09031936.00203511

4. O'Callaghan-Gordo C, Bassat Q, Diez-Padrisa N, et al. Lower respiratory tract infections associated with rhinovirus during infancy and increased risk of wheezing during childhood. A cohort study. PLoS ONE 2013;8(7):e69370. https://doi.org/10.1371/journal.pone.0069370

5. Saha SK, Al Emran HM, Hossain B, et al. Streptococcus pneumoniae serotype-2 childhood meningitis in Bangladesh: A newly recognized pneumococcal infection threat. PLoS ONE 2012;7(3):e32134. https://doi.org/10.1371/journal. pone.0032134

6. Barry MA, Weatherhead JE, Hotez PJ, Woc-Colburn L. Childhood parasitic infections endemic to the United States. Pediatr Clin North Am 2013;60(2):471485. https://doi.org/10.1016/j.pcl.2012.12.011

7. Van Buul LW, van der Steen JT, Doncker SM, et al. Factors influencing antibiotic prescribing in long-term care facilities: A qualitative in-depth study. BMC Geriatr 2014;14(1):136-147. https://doi.org/10.1186/1471-2318-14-136

8. Korhonen L, Kondrashova A, Tauriainen S, et al. Enterovirus infections in early childhood and the risk of atopic disease - a nested case-control study. Clin Exp Allergy 2013;43(6):625-632. https://doi.org/10.1111/cea.12068

9. Lee GC, Reveles KR, Attridge RT. Outpatient antibiotic prescribing in the United States: 2000 to 2010. BMC Med 2014;12(1):96. https://doi. org/10.1186/1741-7015-12-96
10. Bharathiraja R, Sridharan S, Chelliah LR, Suresh S, Senguttuvan M. Factors affecting antibiotic prescribing pattern in pediatric practice. Indian J Pediatr 2005;72(10):877-879. https://doi.org/10.1007/bf02731121

11. Al-Jeraisy MI, Alanazi MQ, Abolfotouh MA. Medication prescribing errors in a pediatric inpatient tertiary care setting in Saudi Arabia. BMC Res Notes 2011;4:294-300. https://doi.org/10.1186/1756-0500-4-294

12. Llor C, Bjerrum L. Antimicrobial resistance: Risk associated with antibiotic overuse and initiatives to reduce the problem. Ther Adv Drug Saf 2014;5(6):229241. https://doi.org/10.1177/2042098614554919

13. World Health Organization. Medicines: Medicines for Children. Geneva: WHO, 2010.

14. Alemnew G, Atnafie SA. Assessment of the pattern of antibiotics use in pediatrics ward of Dessie referral hospital, North East Ethiopia. Int J Med Med Sci 2015;7(1):1-7. https://doi.org/10.5897/ijmms2014.1101

15. Fadare J, Olatunya O, Oluwayemi O, Ogundare O. Drug prescribing pattern for under-fives in a paediatric clinic in south-western Nigeria. Ethiop J Health Sci 2015;25(1):73-78. https://doi.org/10.4314/ejhs.v25i1.10

16. Del Fiol FdeS, Lopes LC, Barberato-Filho S, Motta CdeC. Evaluation of the prescription and use of antibiotics in Brazilian children. Braz J Infect Dis 2013;17:332-337. https://doi.org/10.1016/j.bjid.2012.10.025

17. Zoorob R, Sidani MA, Fremont RD, Kihlberg C. Antibiotic use in acute upper respiratory tract infections. Am Fam Physician 2012;86(9):817-822.

18. Greenfield SP. Antibiotic prophylaxis in pediatric urology: An update. Curr Urol Rep 2011;12(2):126-131. https://doi.org/10.1007/s11934-010-0164-y

19. Song S-H, Kim KS. Antibiotic prophylaxis in pediatric urology. Indian J Urol 2008;24(2):145-149. https://doi.org/10.4103/0970-1591.40605

20. Bryce A, Hay AD, Lane IF, Thornton HV, Wootton M, Costelloe C. Global prevalence of antibiotic resistance in paediatric urinary tract infections caused by Escherichia coli and association with routine use of antibiotics in primary care: Systematic review and meta-analysis. BMJ 2016;352:i939. https://doi. org/10.1136/bmj.i93921.

21. Fisher BT, Meaney PA, Shah SS, Steenhof AP. Short Report: Antibiotic Use in pediatric patients admitted to a referral hospital in Botswana. Am J Trop Med Hyg 2009;81(1):129-131.

22. Bibi S, Chisti MJ, Fau-Akram F, Akram F, Fau-Pietroni MAC, Pietroni MA. Ampicillin and gentamicin are a useful first-line combination for the management of sepsis in under-five children at an urban hospital in Bangladesh. J Health Popul Nutr 2012;30(4):487-490. https://doi.org/10.3329/ jhpn.v30i4.13418

23. Teni FS, Surur AS, Getie A, Alemseged A, Meselu M. Medication prescribing pattern at a pediatric ward of an Ethiopian hospital. Int J Pediatr 2014;2(4.2):2330. https://doi.org/10.22038/ijp.2014.3342

24. Janjua NZ, Hutin YJ, Akhtar S, Ahmad K. Population beliefs about the efficacy of injections in Pakistan's Sindh province. Public Health 2006;120(9):824-833. https://doi.org/10.1016/j.puhe.2006.05.004

25. Krishnan A, Amarchand R, Gupta V, et al. Epidemiology of acute respiratory infections in children - preliminary results of a cohort in a rural north Indian community. BMC Infect Dis 2015;15(1):1-10. https://doi.org/10.1186/s12879015-1188-1 